\title{
Isolated pericardial hydatid cyst: anatomical details on 64 slice multidetector CT scanner
}

\author{
Amit Nandan Dhar Dwivedi, ${ }^{1}$ Shiwani Gupta, ${ }^{1}$ Lovekesh Bhatia, ${ }^{1}$ Suchi Tripathi ${ }^{2}$ \\ ${ }^{1}$ Department of Radiodiagnosis \& Imaging, Institute of Medical Sciences, Varanasi, India \\ ${ }^{2}$ Department of Internal Medicine, Institute of Medical Sciences, Varanasi, India
}

Correspondence to Dr Amit Nandan Dhar Dwivedi, amitnandan21@yahoo.com

\section{DESCRIPTION}

Cardiac involvement is uncommon $(0.02-2 \%)^{1}$ in hydatid disease and the most common location is in the left ventricle, followed by interventricular septum and right ventricle. The clinical presentation of hydatid disease depends on the location of the cysts, and diagnosis is usually made by CT and/or high-resolution MRI. ${ }^{2}$

We are presenting an extremely rare manifestation of hydatid disease in the pericardial sac. Our patient 78-year-old woman of South-Asian descent presented with non-specific chest pain, and we are presenting the striking diagnostic images of a rare manifestation of hydatid disease obtained through the multiplanar capabilities of 64 slice CT scanner, which demonstrates the anatomical details, calcifications and internal architecture of this rare disease in an uncommon location (figures 1-3).

Abdominal ultrasonographic evaluation revealed no other cystic lesion either in the liver or other abdominal organs.

Multidetector CT scanner has the capability of defining the disease in all planes and with its spatial and temporal resolution can achieve diagnostic information on par with MRI scanning. Multiplanar CT also carries the added advantage of being more sensitive in picking up

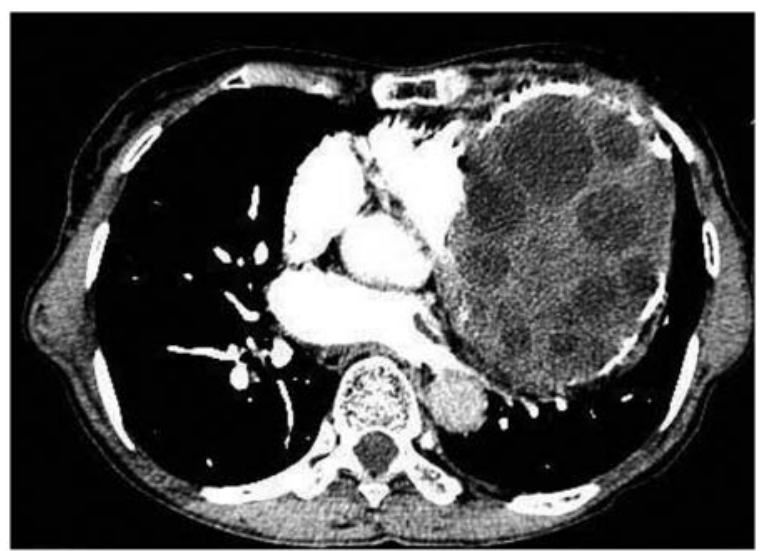

Figure 1 Contrast-enhanced axial section shows multilocular smooth-walled cystic lesion with peripheral wall calcification and multiple daughter cysts arising from the pericardium of left ventricular wall: characteristic hydatid cyst.

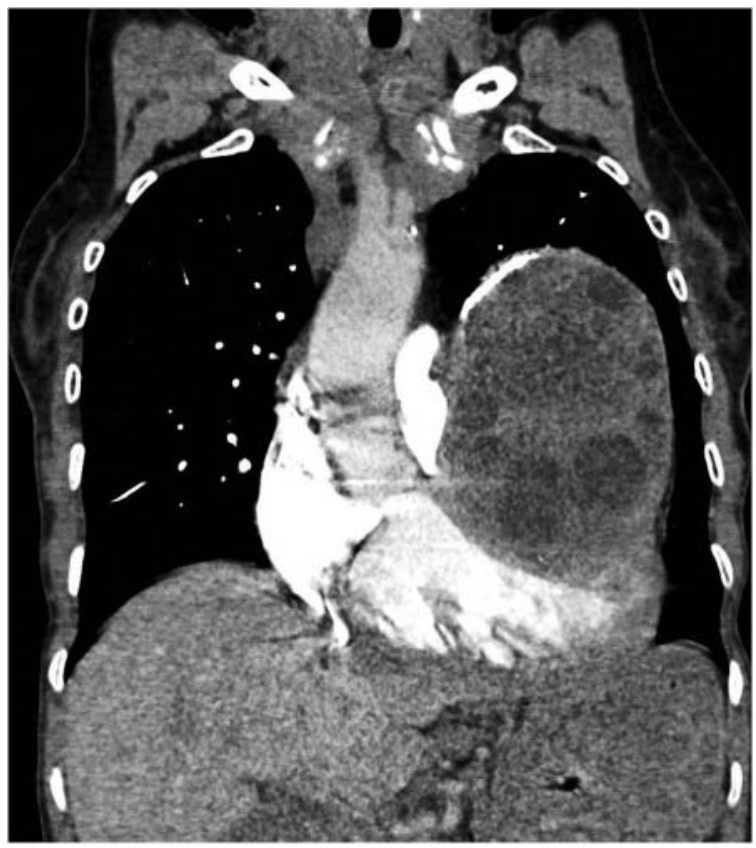

Figure 2 Contrast-enhanced coronal processed image shows the relation of the cyst with left ventricle and pericardium and mass effect on pulmonary artery. Peripheral wall calcification can be seen.

calcifications and pulmonary pathology (where MRI is not as good as CT).

\section{Learning points}

- Multidetector CT scanner has the capability of defining the disease in all planes and with its spatial and temporal resolution can achieve diagnostic information on par with MRI scanning.

- Multiplanar CT also carries the added advantage of being more sensitive in picking up calcifications and pulmonary pathology (where MRI is not as good as CT).

Competing interests None

Patient consent Obtained. 


\section{BMJ Case Reports}

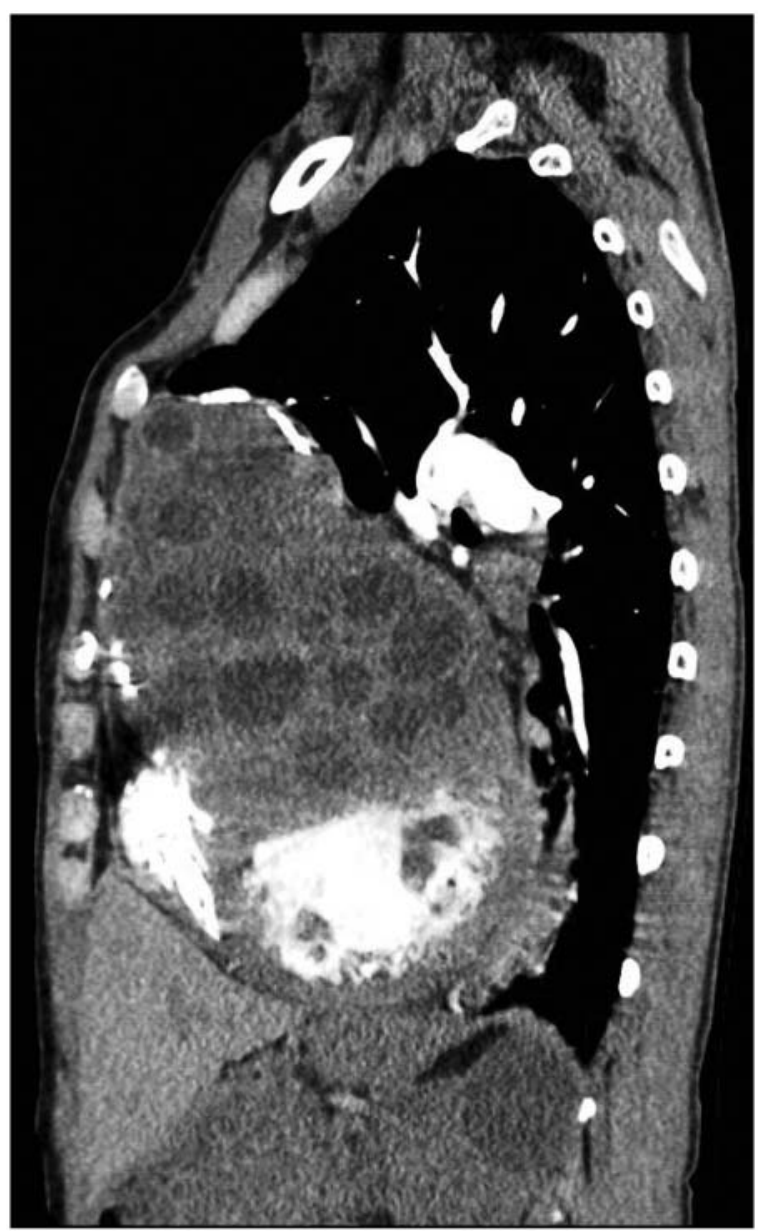

\section{REFERENCES}

1. Karadas F, Karada D, Tselikos A, et al. Fifteen year surveillance of echonococcal heart disease from a referral hospital in Greece. Eur Heart $J$ 1996;17:1265-70.

2. Vural M, Sayin B, Pasaoglu L, et al. Isolated pericardial hydatid cyst in an asymptomatic patient: a remark on its radiologic diagnosis. Clin Imaging 2007:31:37-9.

Figure 3 Contrast-enhanced sagittal processed image shows the antero-posterior relation with mediastinal structures and pericardial origin of left ventricle.

This pdf has been created automatically from the final edited text and images.

Copyright 2012 BMJ Publishing Group. All rights reserved. For permission to reuse any of this content visit http://group.bmi.com/group/rights-licensing/permissions.

BMJ Case Report Fellows may re-use this article for personal use and teaching without any further permission.

Please cite this article as follows (you will need to access the article online to obtain the date of publication).

Dwivedi AND, Gupta S, Bhatia L, Tripathi S. Isolated pericardial hydatid cyst: anatomical details on 64 slice multidetector CT scanner. BMJ Case Reports 2012;10.1136/bcr-2012-006595, Published XXX

Become a Fellow of BMJ Case Reports today and you can:

- Submit as many cases as you like

- Enjoy fast sympathetic peer review and rapid publication of accepted articles

- Access all the published articles

- Re-use any of the published material for personal use and teaching without further permission

For information on Institutional Fellowships contact consortiasales@bmjgroup.com

Visit casereports.bmj.com for more articles like this and to become a Fellow 